\title{
Caracterizando os visitantes do Parque Estadual da Ilha do Cardoso (SP): subsídio para o planejamento de atividades turística-educacional em áreas de manguezal
}

\author{
Characterizing the visitors of the State Park of Cardoso Island (SP, Brazil): \\ support for the planning of tourism and educational activities in \\ mangrove areas
}

\section{Hélita Maria Teixeira Moaes, Marília Cunha Lignon}

\begin{abstract}
RESUMO
O turismo tem causado impactos negativos em unidades de conservação costeiras no Brasil, decorrentes da falta de planejamento da atividade. O presente trabaIho tem como objetivo caracterizar os visitantes do Parque Estadual da Ilha do Cardoso (PEIC), localizado no litoral sul do Estado de São Paulo, a fim de subsidiar o planejamento das atividades turística-educacional em áreas de manguezal. No período entre 2002 e 2006, o Núcleo Perequê, localizado na parte nordeste da Ilha do Cardoso, recebeu 210 grupos de visitantes, totalizando 8.420 pessoas. Os grupos de visitantes variaram entre 2 e 138 pessoas. Cada coordenador dos grupos visitantes preencheu um questionário elaborado por funcionários do PEIC, gerando um total de 210 questionários, entre 2002 e 2006. Informações sobre o número de visitantes, motivo da visita, atividades desenvolvidas, tempo de permanência entre outras eram registradas pelo responsável de cada grupo de visitantes. Os questionários eram preenchidos somente por grupos de visitantes que se hospedavam no PEIC. Os dados foram analisados de forma quantitativa. A maioria dos visitantes do PEIC era formada por grupos de escolas, acompanhadas por agências de turismo especializadas em estudo do meio ambiente. O Núcleo Perequê do PEIC recebeu 8.420 visitantes, entre 2002 e 2006, que pernoitaram nessa UC. A visitação apresentou sazonalidade bem definida, influenciada pelo calendário escolar. A maioria dos grupos de escolas que mais frequentaram o Núcleo Perequê do PEIC foram instituições particulares, provenientes, principalmente das cidades de São Paulo, Campinas e Sorocaba, assim como de Curitiba. Os resultados do presente estudo poderão auxiliar na elaboração de recomendações de modo a minimizar os impactos negativos causados pelas atividades desenvolvidas e maximizar as qualidades das experiências turística-educacionais obtidas durante a visitação em áreas de manguezal.
\end{abstract}

PALAVRAS-CHAVE: Visitante; Manguezal; Unidade de Conservação. 
Caracterizando os Visitantes do Parque Estadual da llha do Cardoso (SP): subsídio para o planejamento de atividades turística-educacional em áreas de manguezal

\section{ABSTRACT}

Tourism has caused negative impacts on protected coastal areas in Brazil, due to lack of planning activity. The present work aims to characterize the visitors to the State Park of Cardoso Island (PEIC), located on the southern coast of São Paulo in order to support the planning of tourism and educational activities in mangrove areas. Between 2002 and 2006, the Perequê Center, located in the northeastern part of the Cardoso Island, received 210 groups of visitors, totaling 8,420 people. The visitor groups ranged from 2 to 138 people. Each coordinator of the visiting groups completed a questionnaire prepared by PEIC, generating a total of 210 questionnaires between 2002 and 2006. Information on the number of visitors, purpose of visit, activities, length of stay, among other were recorded only by the person responsible for each group of visitors. The questionnaires were filled only by groups of visitors who were staying in PEIC. Data were analyzed quantitatively. Most visitors PEIC was formed by groups of schools, accompanied by travel agencies specializing in the study of the environment. The Perequê Center received 8,420 visitors between 2002 and 2006, which stayed at this protected area. The visit showed well defined seasonality influenced by the school-year. The majority of school groups that attended most of the Perequê Center were private institutions, coming mainly from São Paulo, Campinas, Sorocaba and Curitiba cities. The results from this study can assist recommendations to minimize the negative impacts caused by activities and maximize the quality of tourism and educational experiences obtained during the visitation in mangrove areas.

KEYWORDS: Visitor; Mangrove; Protected Area.

\section{Introdução}

As regiões litorâneas e costeiras do Brasil apresentam uma multiplicidade de ecossistemas extremamente produtivos, onde se destacam os ecossistemas estuarinos, manguezais, recifes de corais e planícies inundáveis (DIEGUES, 1987). Os manguezais são considerados entre os ambientes costeiros mais importantes do planeta. São ecossistemas característicos das zonas estuarinas tropicais e subtropicais. As espécies vegetais típicas dos manguezais são denominadas mangues, as quais apresentam uma série de adaptações morfológicas, fisiológicas e reprodutivas comuns, que as permitem desenvolver-se em ambientes instáveis e estressantes. Sob condições ambientais apropriadas, os mangues podem formar bosques extensos e produtivos, sendo utilizados por populações humanas costeiras como um importante recurso econômico, há milhares de anos (DUGAN, 1992).

O ecossistema manguezal já foi muito associado ao mal cheiro, insetos e poluição. A medida que surge um turismo voltado para a vida silvestre e a pesca esportiva, essas áreas passam a ser valorizadas. Avau et al. (2011) afirma que passeios em manguezais tem sido apresentados em pacotes turísticos na Jamaica, Guadalope e Martinica (Caribe). Satyanarayana et al. (2012) destacaram a im- 
portância do ecoturismo em áreas de manguezal realizado em países da África, apresentando equilíbrio entre o uso de recursos naturais pelas comunidades humanas locais, conservação e gestão dos manguezais. No Brasil, esse ecossistema vem aos poucos sendo procurado para atividades turísticas, atraindo pessoas que realizam passeios de barco, observação de pássaros, fotografia e principalmente educação ambiental (DIEGUES, op. cit.).

Segundo Cintrón (1987), atividades de recreação, turismo, pesca, educação e pesquisa em manguezais são possíveis de serem desenvolvidas e compatibilizadas com a conservação e não requerem grandes manejos nos sistemas. Se não forem minimamente planejadas, estas atividades poderão ocasionar importantes alterações locais. Maciel (1987) enfatiza que o melhor uso para qualquer manguezal é continuar como área protegida, mantendo valores culturais, estéticos, paisagísticos, recreacionais, educacionais, estabilização da linha de costa, proteção da vida e dos recursos pesqueiros. Para isso, é necessário melhorar, tanto em quantidade como em qualidade, as informações sobre os manguezais e seus valores, funções e serviços. É fundamental que todos os níveis da sociedade (público em geral, comunidades locais, ONGS e governo) compreendam melhor a importância dos manguezais (DUGAN, 1992).

A análise dos impactos do turismo, tanto positivos como negativos tem revelado a necessidade de estabelecer critérios globais e multidimensionais nas políticas do turismo em diversas escalas (RODRIGUES, 1997). Segundo Lugo (2002), pesquisas considerando múltiplas escalas espaço-temporais, assim como a participação de todos os setores da sociedade na gestão de áreas de manguezal contribuem para melhorar de forma efetiva a conservação desse ecossistema. Davenport e Davenport (2006) alertam para a importância da gestão da atividade de ecoturismo na zona costeira, de modo a se evitar impacto-s na região visitada.

Os impactos negativos que o turismo pode ocasionar em uma dada região são inúmeros, podendo estar relacionados aos aspectos econômicos, socioculturais e ambientais (RUSCHMANN, 1999). Uma simples trilha em áreas naturais pode causar impactos ambientais negativos e o pisoteio pode compactar o solo, diminuir o teor de infiltração das águas e eliminar a vegetação. Seabra (2005) afirma que o reduzido número de estudos sobre os impactos causados pelo turismo no Brasil, restringe a implantação de medidas que possam estabelecer os limites de carga turística suportável em cada área. Segundo Costa et al. (2007), as caminhadas em trilhas oferecem grande contato do turista com a natureza e exigem infraestrutura e manejo apropriados a demanda dos usuários, sobretudo em áreas de elevado potencial turístico, sendo consideradas o principal veículo condutor das práticas ecoturísticas, de lazer e de recreação. Segundo os autores, as trilhas são os primeiros elementos de infraestrutura a serem instalados na implementação da UC, sendo a erosão das mesmas um dos principais impactos negativos decorrentes do uso público de UCs brasileiras (BRASIL, 2003). 
Caracterizando os Visitantes do Parque Estadual da llha do Cardoso (SP): subsídio para o planejamento de atividades turística-educacional em áreas de manguezal

Nas UCs passíveis de visitação, a prática do turismo de massa aliada a falta de infraestrutura precária e mão de obra limitada têm aumentado a degradação do meio natural nessas áreas (SEABRA, 2005). Para o manejo de UCs, a disponibilidade de conhecimento é essencial para subsidiar ações que visam à conservação da biodiversidade (GUAPYASSÚ, 2006). Pesquisas desenvolvidas nas UCs podem contribuir diretamente para a melhoria da compreensão das espécies animais e vegetais (GUAPYASSÚ, op. cit.), assim como das relações entre os visitantes e os ecossistemas visitados. Informações sobre as características básicas dos visitantes de uma UC auxiliam pesquisadores e administradores a compreenderem o comportamento dos usuários, bem como as causas e potenciais soluções dos impactos negativos causados (KATAOKA, 2004). A caracterização dos visitantes das UCs é ferramenta valiosa para auxiliar na administração e na conservação dessas áreas (NIEFER, 2000). Uma das etapas necessárias no processo de elaboração de diretrizes para visitação em UCs consiste em entender e diagnosticar a situação atual dessas atividades (BRASIL, 2003).

Hall (2001), a partir de compilação dos impactos ambientais e ecológicos do turismo em ecossistemas costeiros, destacou a destruição de manguezais por excessiva visitação, a falta de manejo sobre a exploração de recursos do ecossistema e substituição de áreas de manguezal por marinas e resorts. Ramsar (2004) cita estudos de caso na Malásia, Mauritânia, México e Tanzânia onde há impactos em área de manguezal, decorrentes do turismo sem planejamento, entre outras atividades humanas.

\section{Objetivos}

O presente estudo tem como objetivo caracterizar os visitantes do Parque Estadual da llha do Cardoso (PEIC), localizado no litoral sul do Estado de São Paulo, a fim de subsidiar o planejamento das atividades turística e educacional, em áreas de manguezal, as quais apresentavam impactos decorrentes da visitação.

\section{Material e Métodos}

\section{Área de Estudo}

O presente trabalho foi realizado no Parque Estadual da Ilha do Cardoso (PEIC), localizado no extremo sul do litoral do Estado de São Paulo, Município de

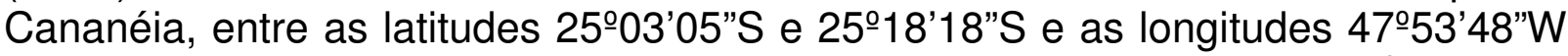
e $48^{\circ} 05^{\prime} 42^{\prime \prime} \mathrm{W}$ (Figura 1). A temperatura média anual na região é de $23,8^{\circ} \mathrm{C}$, sendo a temperatura média mensal mais alta $27,8^{\circ} \mathrm{C}$, ocorrendo em fevereiro, e a média mensal mais baixa $19,8^{\circ} \mathrm{C}$, em julho (SILVA, 1989).

O Município de Cananéia fica a $258 \mathrm{~km}$ de distância da cidade de São Paulo, a $260 \mathrm{~km}$ de Curitiba e a $244 \mathrm{~km}$ da cidade de Santos. No período do estudo (2006), a população estimada de Cananéia era de 14.195 habitantes (IBGE, 2007). O PEIC possuía cerca de 400 habitantes, moradores tradicionais da llha do 
Cardoso (SÃO PAULO, 1998).

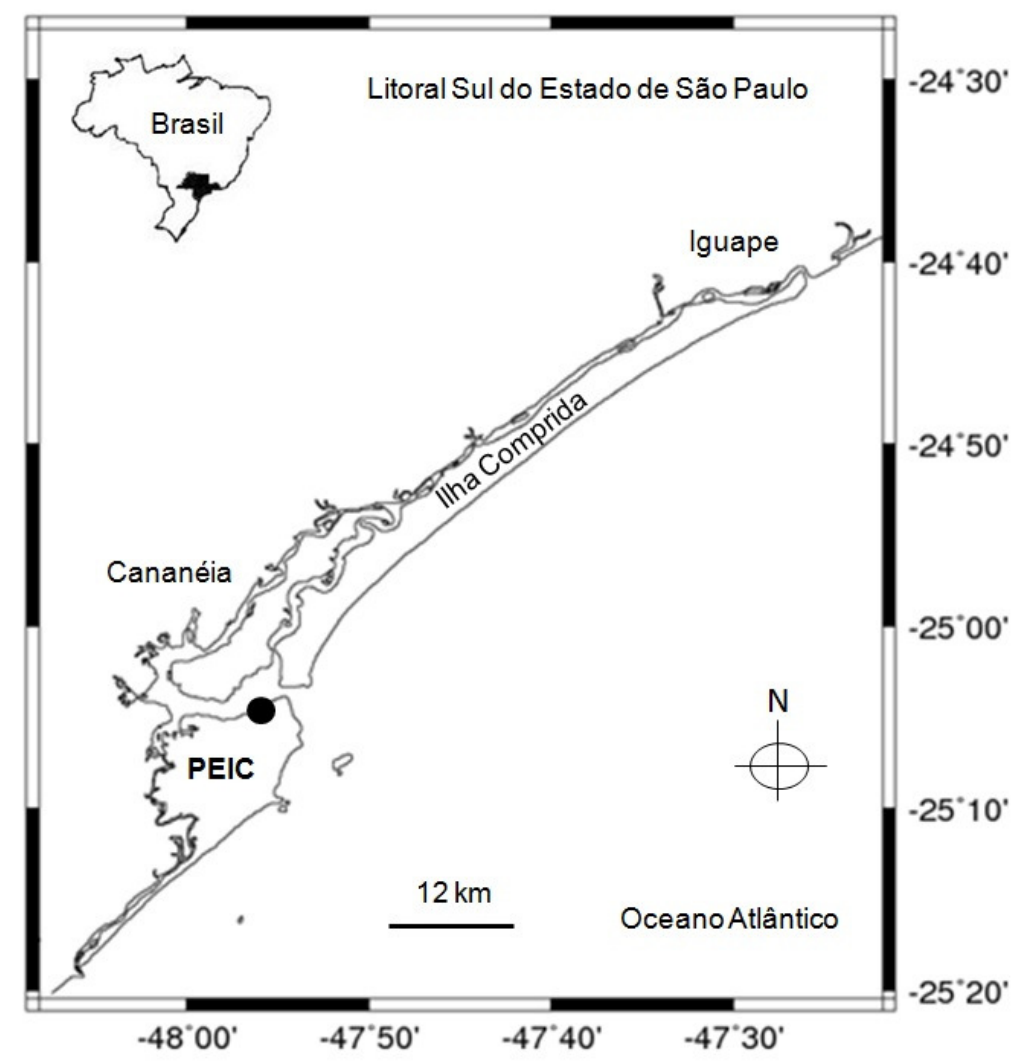

Figura 1: Localização do Parque Estadual da llha do Cardoso (PEIC), no litoral sul de São Paulo. Destaque para o Núcleo Perequê.

Figure 1: State Park of Cardoso Island (PEIC) location, on southern littoral of São Paulo.

Focus on Perequê Nucleus.

A diversidade paisagística dessa região, formada por manguezais, restingas, floresta atlântica, praias, estuário, rios e alagados proporciona alta diversidade biológica e mosaicos de cenários que despertam grande interesse turístico. A íntima relação de espécies da fauna litorânea brasileira com os ecossistemas costeiros seja para abrigo, alimentação, reprodução e/ou nidificação, faz com que a conservação desses ambientes torne-se cada vez mais importante (CUNHA-LIGNON et al., 2000).

Cunha-Lignon et al. (op. cit.) estudaram a relação entre os turistas e o sistema costeiro, traçando o perfil destes no litoral sul de São Paulo. Segundo os autores a porção norte do sistema costeiro recebe turismo de massa, com atividades sendo realizadas na praia da Ilha Comprida, enquanto que grande parte dos turistas da porção sul também realiza atividades no estuário, como passeios de barcos, caminhadas em trilhas da floresta atlântica e utilizam os serviços dos monitores ambientais locais.

O Parque Estadual da llha do Cardoso (PEIC) foi criado em 1962, sendo o primeiro parque insular do Estado de São Paulo. O PEIC abrange uma área de 22.500 
Caracterizando os Visitantes do Parque Estadual da Ilha do Cardoso (SP): subsídio para o planejamento de atividades turística-educacional em áreas de manguezal

ha (SÃO PAULO, 1998). É uma Unidade de Conservação de Proteção Integral, onde são mantidos os ecossistemas livres de alterações causadas por interferência humana, admitindo apenas o uso indireto dos seus atributos naturais, como pesquisas científicas, educação, interpretação ambiental e turismo ecológico. Seu objetivo básico é preservar a natureza, sendo admitido apenas o uso indireto dos seus recursos naturais, com exceção dos casos previstos pelo Sistema Nacional de Unidades de Conservação (SNUC, 2000). O Plano de Gestão Ambiental (PGA) do PEIC foi criado em 1997, com ampla participação de diversos setores da comunidade. O PGA tem por finalidade definir zoneamento, programas de educação ambiental e ecoturismo, pesquisa, conservação dos ecossistemas e interação socioambiental de modo a solucionar e minimizar conflitos nas UCs (SÃO PAULO, op.cit.).

O Núcleo Perequê (Figura 1), localizado na parte nordeste da ilha, possuia refeitório, museu, laboratórios, auditório, loja de souvenires e aquários. Entre 2002 e 2006, tinha capacidade para hospedar até 102 pessoas e receber visitação durante todo $o$ ano (CANANET, 2006). Para 0 atendimento aos visitantes e pesquisadores, 0 PEIC contava com os serviços de funcionários do parque, assim como de monitores ambientais locais. A maioria dos monitores locais faziam parte da Associação de Monitores Ambientais de Cananéia (AMOAMCA), criada em março de 2001, com sede na cidade de Cananéia.

\section{Processamento dos Dados}

O PEIC aplicava sistematicamente questionários aos seus visitantes, que se hospedavam no Núcleo Perequê, a fim de melhorar a qualidade dos equipamentos e infra-estrutura para visitação. Informações sobre o número de visitantes, monitoria ambiental e funcionários, motivo da visita, vínculo, tempo de permanência e sugestões eram registradas a cada visita. Os questionários não eram preenchidos pelos visitantes de um dia, ou seja, aqueles que não se hospedavam no PEIC.

A presente pesquisa utilizou as informações desses questionários citados para determinar o perfil do visitante no ecossistema manguezal do PEIC de janeiro de 2002 a junho de 2006. Os resultados dos questionários constituiram os dados principais, que foram analisados pelo presente estudo de forma quantitativa.

Segundo Pereira (2004), há necessidade de transformar dados qualitativos (amostragem) em quantitativos (tabulação dos resultados), processamento matemático e estatístico de dados, para permitir a revelação de informações que não estão imediatamente aparentes nas medidas originais feita de um objeto ou evento. Dessa forma, os dados qualitativos foram transformados em quantitativos, utilizandose planilha excel em formas de tabelas. A partir destas, foram construídas outras tabelas que possuíam o valor absoluto amostrado e os valores em porcentagem. De modo a auxiliar na avaliação da visitação dos manguezais no PEIC, foram realizadas entrevistas semiestruturadas com os monitores ambientais.

Os monitores entrevistados foram escolhidos pelo tempo de trabalho na AMOAMCA "Associação dos Monitores Ambientais de Cananéia" e no PEIC, logo deu 
-se prioridade aos monitores mais antigos da associação. Cada entrevista durou em média de 30 minutos e foi realizada no dia 12/08/2006.

Em março e abril de 2012 foram realizadas entrevistas com a atual diretora do PEIC, funcionários do PEIC e monitores ambientais, a fim de levantar informações sobre as condições atuais de turismo nessa UC.

\section{Resultados e Discussão}

Cada questionário foi preenchido apenas pelo responsável de cada grupo de visitantes, o que correspondeu a 210 questionários respondidos, entre 2002 e 2006. Nesse período, o Núcleo Perequê do PEIC recebeu 8.420 visitantes, que pernoitaram nessa unidade de conservação (Tabela I).

Observa-se grande diferença no tamanho dos grupos, variando entre 2 e 138 visitantes por grupo (Tabela I). Os anos de 2002, 2003 e 2006 foram os mais regulares, em termos de visitação, com 2.339 visitantes por ano, em média (Figura 2 e Tabela I). A queda da visitação nos anos 2004 e 2005 refletiu o reduzido número de questionários respondidos nesse mesmo período (Figuras 2 e 3 e Tabela I). Esse fato não pôde ser explicado pelos funcionários do PEIC, não sendo possível definir se o número reduzido de questionários deve-se à baixa do turismo nessa UC, entre $2004 \mathrm{e}$ 2005, ou à organização interna do parque, em relação ao arquivamento dos questionários aplicados.

Tabela I: Número de questionários respondidos por ano, menor e maior número de pessoas nos grupos e número total de visitantes no PEIC, de 2002 a 2006.

Table I: Number of answered questionnaires by year, the smallest and the biggest number of people in groups and total number of visitors on PEIC, from 2002 to 2006.

\begin{tabular}{|l|c|c|c|}
\hline Ano & $\begin{array}{c}\mathbf{N}^{\mathbf{0}} \text { de Questionários Res- } \\
\text { pondidos }\end{array}$ & $\begin{array}{c}\text { Maior e Menor } \mathbf{N}^{\mathbf{0}} \text { de } \\
\text { Pessoas por Grupo }\end{array}$ & Total de Visitantes \\
\hline 2002 & 66 & 2 a 138 & 2.378 \\
\hline 2003 & 58 & 2 a 127 & 2.306 \\
\hline 2004 & 08 & 31 a 98 & 474 \\
\hline 2005 & 23 & 11 a 81 & 929 \\
\hline 2006 & 55 & 14 a 130 & 2.333 \\
\hline Total & $\mathbf{2 1 0}$ & --- & $\mathbf{8 . 4 2 0}$ \\
\hline
\end{tabular}

O Parque Estadual da Ilha Anchieta (PEIA), localizado no litoral norte do Estado de São Paulo, recebe 80.000 visitantes por ano, representando o $4^{\circ}$ parque estadual brasileiro em número de visitantes (BRASIL, 2003). Pedrini et al. (2007) registraram inúmeros impactos negativos ocasionados por turistas na piscina natural na Praia do Engenho, no PEIA. Segundo os autores, o problema da visitação sem controle nessa UC é antigo e de solução conflitante, uma vez que há décadas todas as escunas que levam visitantes à ilha indicam essa região como atrativo para banho e lazer. Apesar do número de visitantes anual do PEIC ser muito inferior ao do PEIA, é funda- 
Caracterizando os Visitantes do Parque Estadual da Ilha do Cardoso (SP): subsídio para o planejamento de atividades turística-educacional em áreas de manguezal

mental considerar a fragilidade do ecossistema visitado, assim como a falta de equipamentos de infraestrutura para as atividades realizadas.

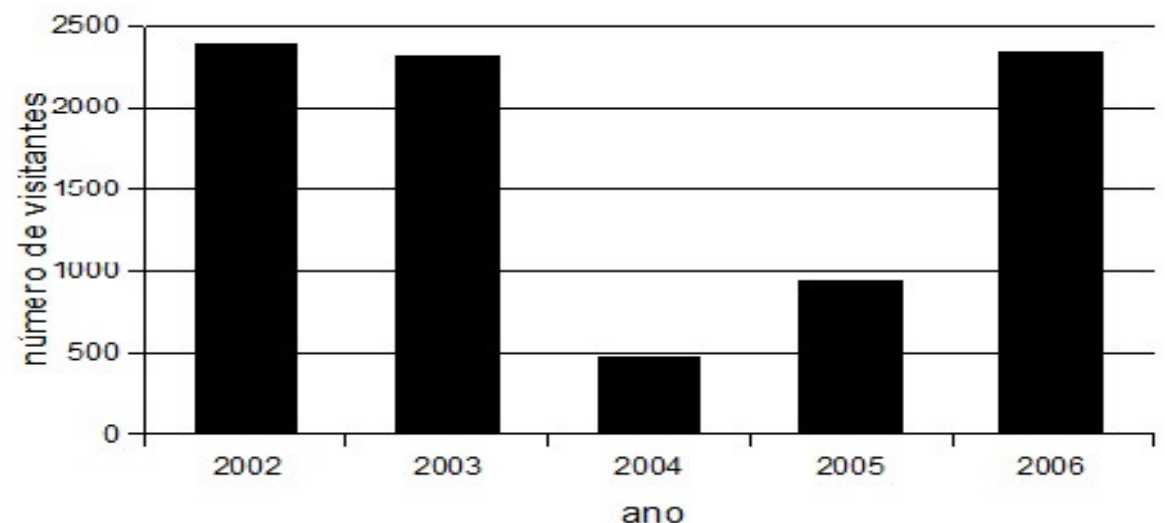

Figura 2: Número de visitantes hospedados no Núcleo Perequê do PEIC, por ano, entre 2002 e 2006.

Figure 2: Number of visitors staying in Perequê Nucleus of PEIC, per year, between 2002 and 2006.

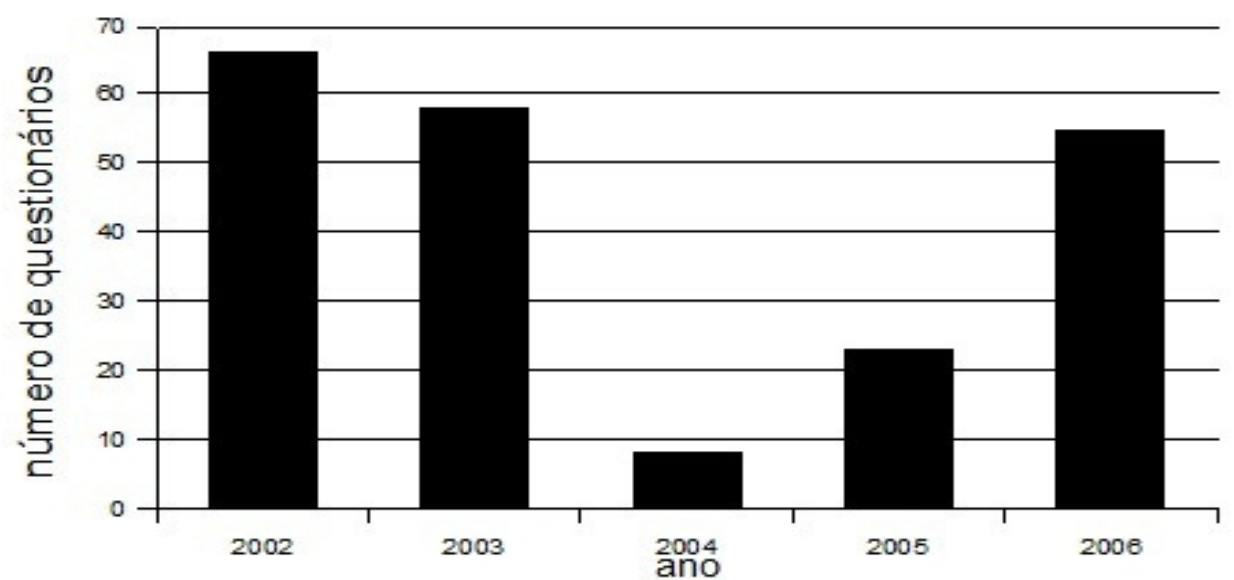

Figura 3: Número de questionários aplicados aos responsáveis dos grupos de visitantes no Núcleo Perequê do PEIC, entre 2002 e 2006.

Figure 3: Number of questionnaires applied to visitors' group leaders in Perequê Nucleus of PEIC, between 2002 and 2006.

A partir das respostas dos questionários do PEIC, as atividades desenvolvidas pelos visitantes foram agrupadas em três classes: educativa, trabalho e lazer (Figura 4). Observa-se claramente que a atividade educativa foi a mais importante, variando entre 77 e $100 \%$. As atividades educativas desenvolvidas no PEIC são realizadas por grupos de escolas, universidades e outras instituições. Os grupos de escolas destacam-se com valores acima de $70 \%$ (Figuras 5 e 6). Os ecossistemas visitados pelos grupos de escolas no PEIC são manguezal (Figura 6), restinga, praia, floresta atlântica e costão rochoso. 


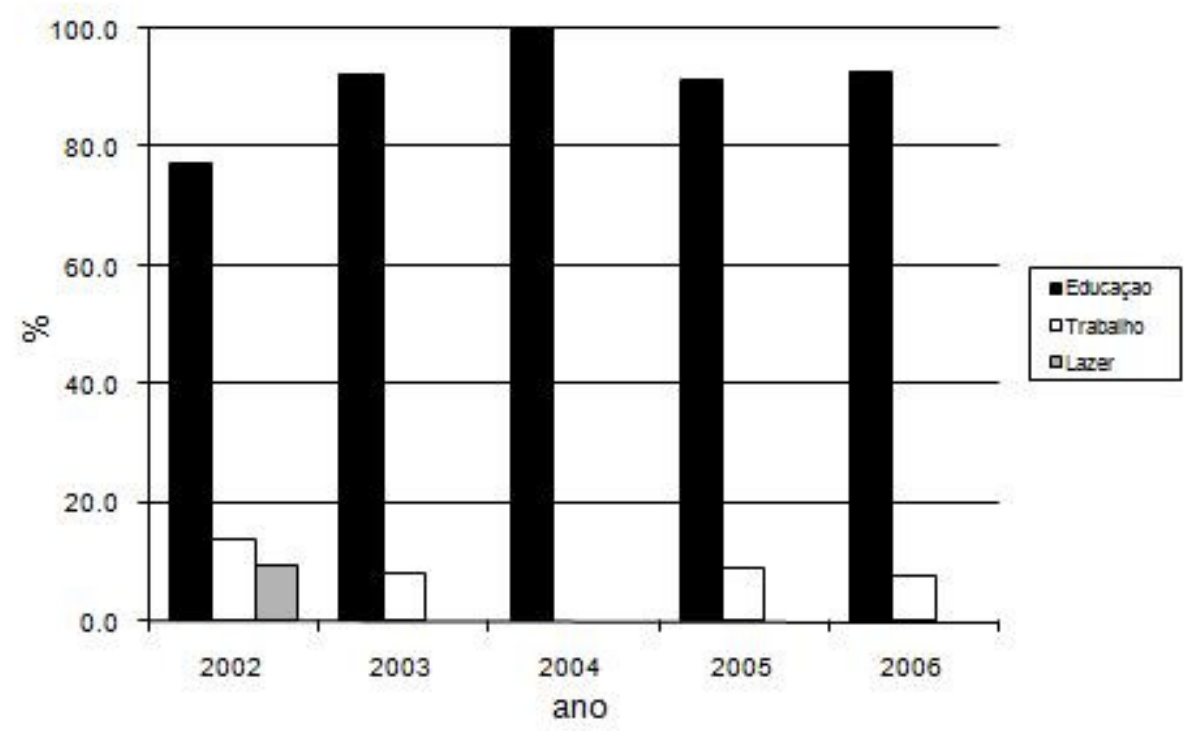

Figura 4: Atividades desenvolvidas pelos visitantes no Núcleo Perequê do PEIC, entre 2002 e 2006, em porcentagem.

Figure 4: Activities undertaken by visitors in Perequê Nucleus of PEIC, between 2002 and 2006, in percentage.

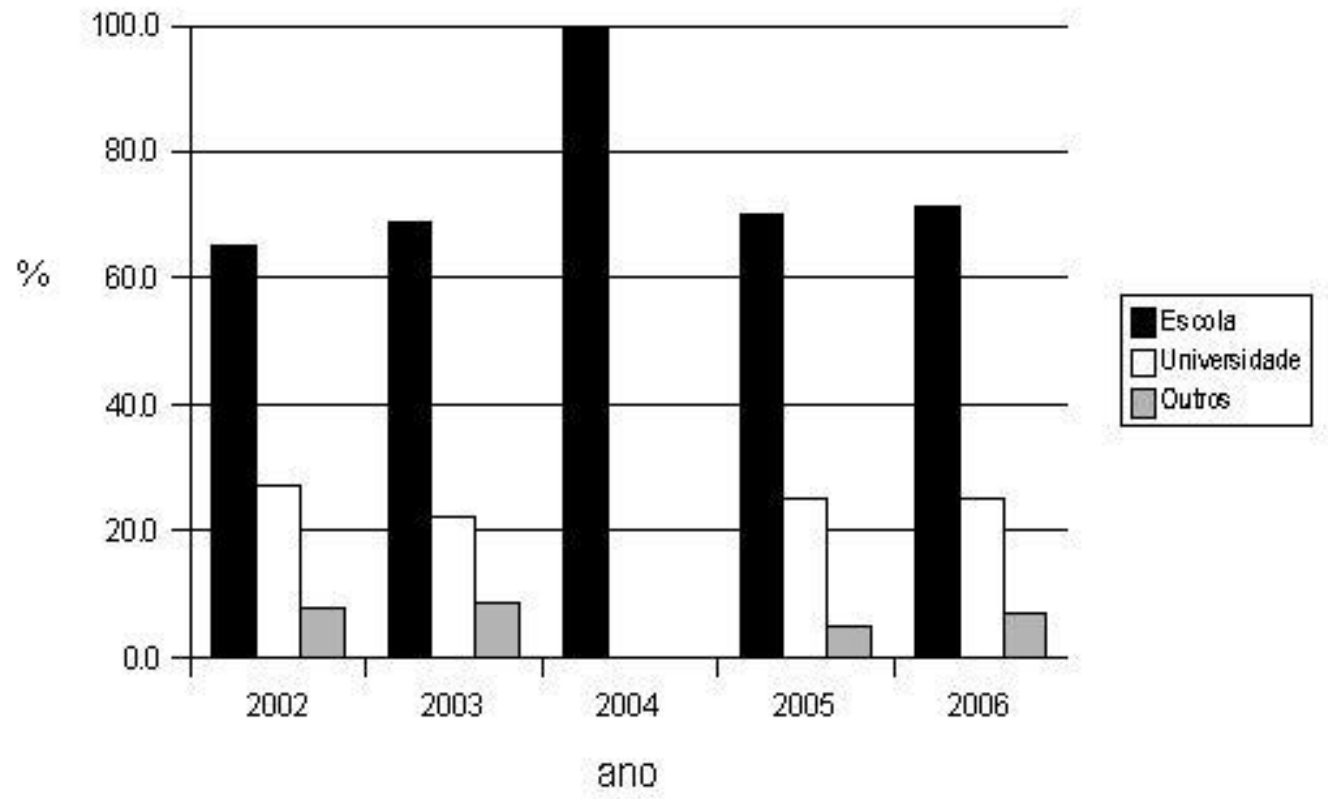

Figura 5: Instituições educacionais que visitaram o Núcleo Perequê do PEIC, entre 2002 e 2006, em porcentagem.

Figure 5: Educational institutions which visited Perequê Nucleus of PEIC, between 2002 and 2006, in percentage. 
Caracterizando os Visitantes do Parque Estadual da Ilha do Cardoso (SP): subsídio para o planejamento de atividades turística-educacional em áreas de manguezal

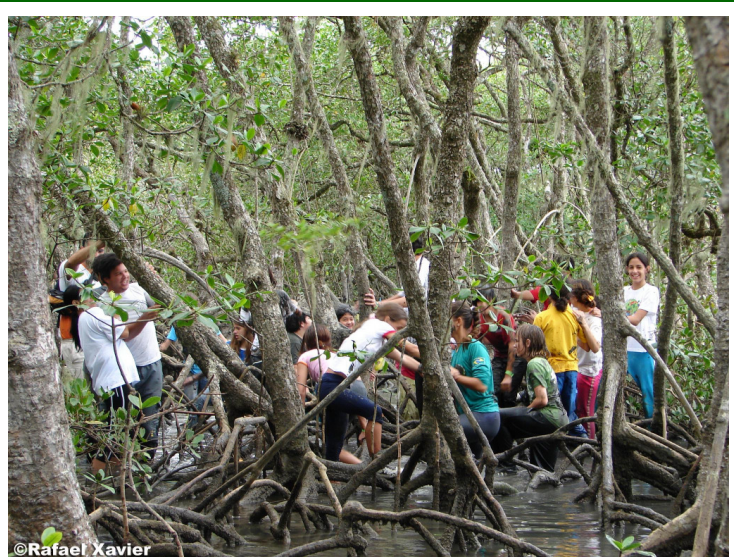

Figura 6: Visitação de alunos do ensino fundamental no manguezal do Núcleo Perequê do PEIC.

Foto: Rafael Xavier (2012).

Figure 6: Elementary school students visiting the mangrove of Perequê Nucleus.

Photo: Rafael Xavier (2012).

Observa-se que grande parte das escolas que visitavam o PEIC utilizavam os serviços de agências de turismo especializadas em estudo do meio ambiente, variando entre 65 e 87\%, em 2003 e 2006, respectivamente (Figura 7). Além disso, essas agências contratavam o serviço de funcionários do próprio PEIC e de monitores ambientais locais, credenciados na Associação de Monitores Ambientais de Cananéia (AMOAMCA), como também monitores ambientais autônomos no entorno do parque estadual. Atualmente a AMOAMCA não presta mais serviços ao PEIC, os monitores ambientais trabalham como autônomos. A direção do PEIC afirmou ter interesse de que a associação continue existindo.

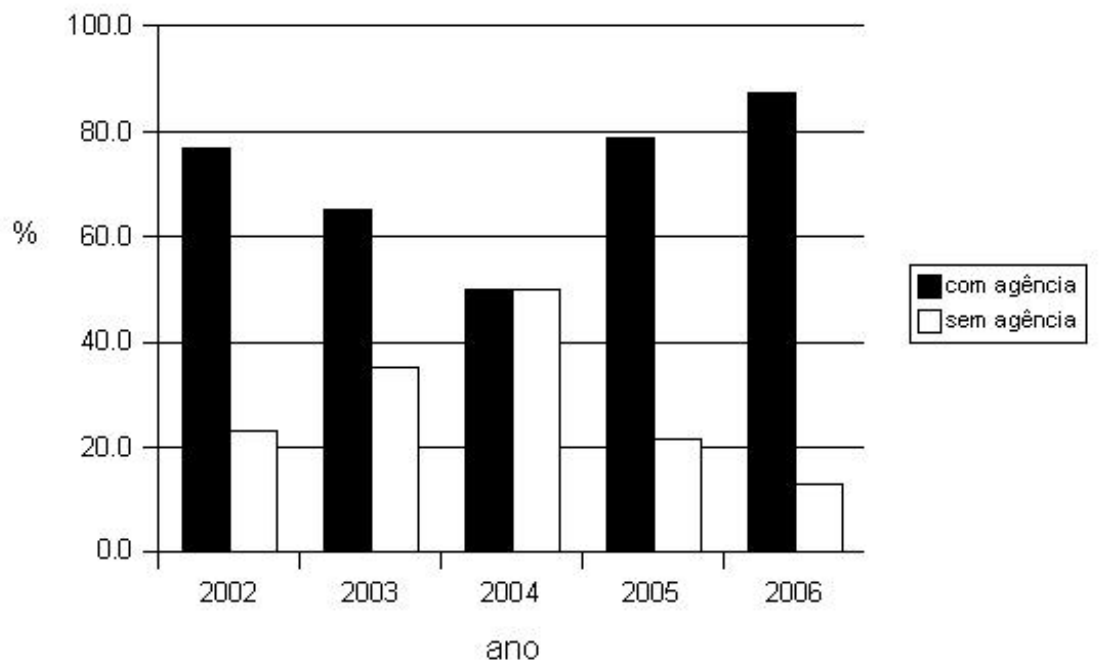

Figura 7: Porcentagem de escolas visitantes no Núcleo Perequê do PEIC, acompanhadas e não acompanhadas por agências especializadas em estudo do meio ambiente, entre 2002 e 2006.

Figure 7: Percentage of school visitors in Perequê Nucleus of PEIC, accompanied and unaccompanied by specialized agencies of the environmental study, between 2002 and 2006. 
A maioria das atividades desenvolvidas nas UCs brasileiras está vinculada às caminhadas, trilhas interpretativas e visitas de escolas (BRASIL, 2003). Costa et al. (2007) afirmam que a trilha guiada requer a presença de um monitor ambiental ou guia treinado para acompanhar os visitantes e levá-los a observar, sentir e experimentar o ambiente visitado. Em relação à visitação em UCs do país, a maioria dos parques nacionais não possuem seus próprios guias, sendo as atividades realizadas por guias provenientes do entorno do parque ou, em menor escala, por empresas de turismo locais ou de outras regiões (BRASIL, 2003). Por outro lado, a maioria das atividades de visitação nos parques estaduais do país são realizadas com acompanhamento de guias, guarda-parque, estagiários e voluntários que atuam na UC no momento da visita (BRASIL, 2003). O credenciamento e a regulamentação dos prestadores de serviços turísticos dentro da UC (monitores, guias, operadoras e agentes de viagem) devem ser realizados pelos gestores da UC (BRASIL, 2006).

No PEIC, o questionário aplicado aos grupos de visitantes também faz referência à avaliação dos serviços dos guias da UC e monitores ambientais locais. Os resultados indicaram que as visitas guiadas foram consideradas ótimas entre 85 e $100 \%$ para os guias do parque e 87 e $100 \%$, para os monitores ambientais (Figura 8 ). A avaliação positiva refletiu a dedicação e capacitação constantes dos guias do PEIC e monitores ambientais locais. O estreito contato do PEIC com os monitores ambientais da região valorizou o jovem morador do entorno dessa UC, envolvido com atividades de turismo e educação ambiental.

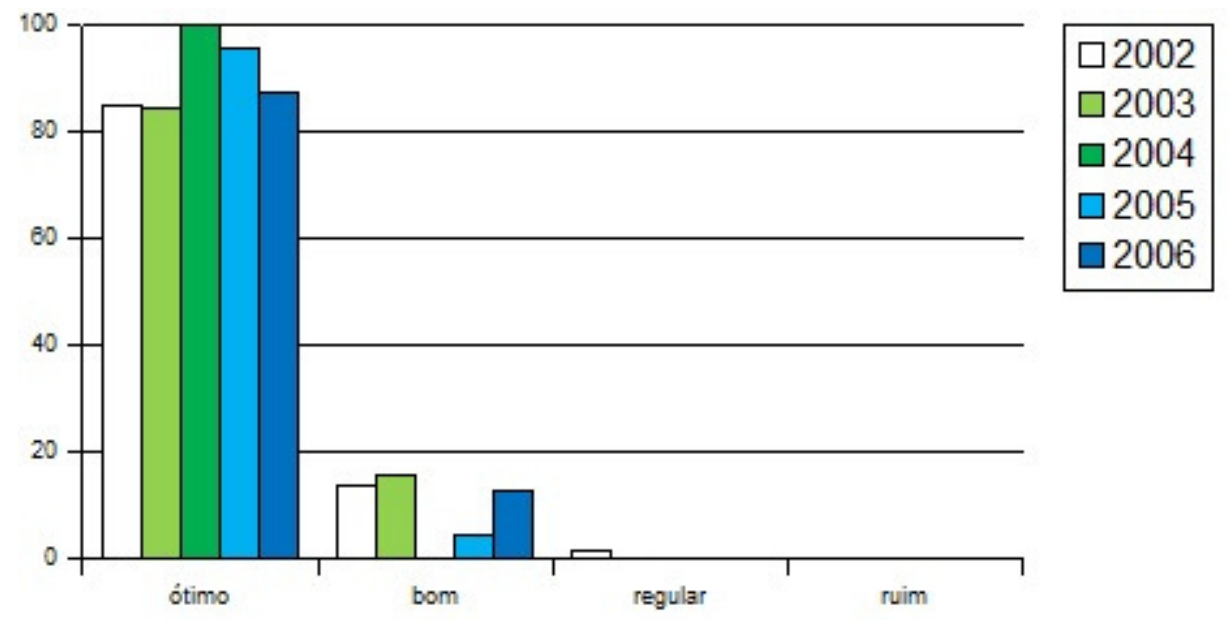

Figura 8: Avaliação dos monitores ambientais locais, pelos grupos de visitantes no PEIC, entre 2002 e 2006.

Figure 8: Assessment of local environmental monitors, by groups of visitors in PEIC, between 2002 and 2006.

Monitores ambientais e guias desempenham importante papel na experiência do visitante, proporcionando grande incremento educativo e interpretativo durante a visita (BRASIL, 2006). A capacitação dos mesmos deve ser estimulada, assim como 
Caracterizando os Visitantes do Parque Estadual da Ilha do Cardoso (SP): subsídio para o planejamento de atividades turística-educacional em áreas de manguezal

um sistema de avaliação e desempenho dos guias e monitores com vistas à qualificação e adequação dos serviços oferecidos devem ser efetuados. A carência de recursos humanos em geral, a falta de informação e orientação para o visitante e capacitação são considerados os principais entraves ao desenvolvimento da visitação em parques estaduais brasileiros (BRASIL, 2003).

As escolas que mais frequentaram o Núcleo Perequê do PEIC, durante o período estudado, foram instituições particulares, provenientes, principalmente das cidades de São Paulo, Campinas e Sorocaba, assim como de Curitiba. O item 'nível escolar' não foi solicitado no questionário elaborado pelo PEIC, mas de modo geral, os estudantes frequentavam o $7^{\circ}$ ano do ensino fundamental quando estudam os seres vivos e suas interações no programa escolar. As agências especializadas, em sua grande maioria com sede na capital paulista, organizavam o transporte das cidades de origem até Cananéia e o PEIC, contratavam monitores com nível universitário, em geral vindos da cidade de São Paulo, assim como faziam o contato com os monitores locais.

Nos anos mais regulares (2002, 2003 e 2006), a visitação no PEIC apresentou sazonalidade bem marcada, influenciada pelo calendário escolar (Figura 9). Os meses de maior visitação foram abril, maio e junho, no $1^{\circ}$ semestre de cada ano, e agosto, setembro, outubro e novembro, no $2^{\circ}$ semestre (Figura 9). A visitação apresentou queda nos meses de janeiro, julho e dezembro, devido às férias escolares (Figura 9). Os grupos de visitantes, que se hospedaram no PEIC, ficaram entre 2 e 12 dias, sendo que destacou-se o tempo de permanência de três dias (Figura 10).

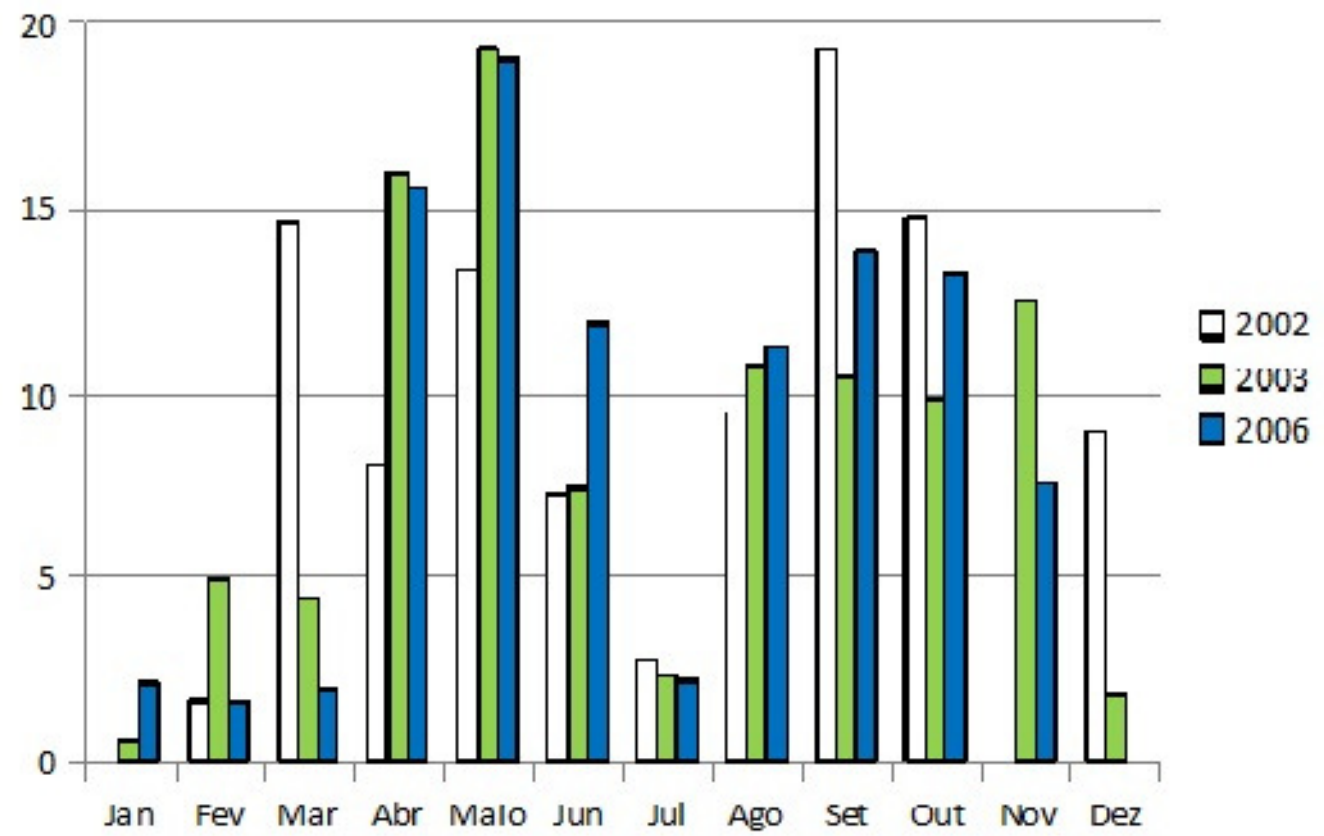

Figura 9: Porcentagem de visitantes no PEIC, por mês, nos anos de 2002, 2003 e 2006.

Figure 9: Percentage of visitors in PEIC, per month, in 2002, 2003 and 2006. 


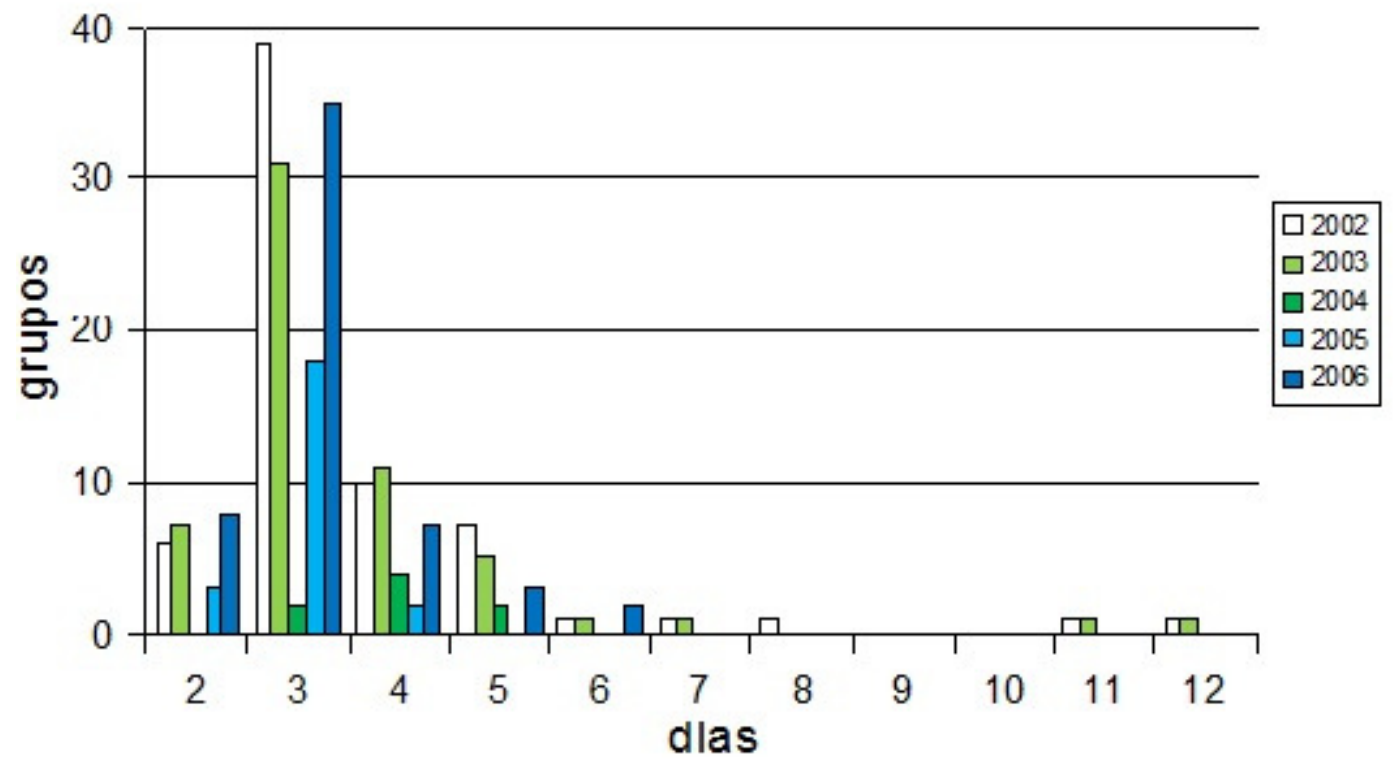

Figura 10: Tempo de permanência, em dias, dos grupos visitantes no Núcleo Perequê do PEIC, entre 2002 e 2006.

Figure 10: Length of staying in days, groups of visitors in Perequê Nucleus of PEIC, between 2002 and 2006.

Segundo a administração do Parque Estadual da llha Anchieta (KATAOKA, 2004), localizado no litoral norte do Estado de São Paulo, as médias mensais de visitantes, entre os anos de 2000 e 2003, variaram de 18.065 a 1.015 pessoas, sendo o verão o período de maior visitação, com médias de 18.065, 8.832 e 7.574 visitantes em dezembro, janeiro e fevereiro, respectivamente. Nesse caso, a visitação está relacionada à estação mais quente do ano e ao período de férias.

Segundo o Art. $4^{\circ}$ do SNUC (2000), uma UC deve 'favorecer condições e promover a educação e interpretação ambiental, a recreação em contato com a natureza e o turismo ecológico'. Takahashi (1997 apud NIEFER, 2000.) afirma que maioria das áreas recreativas é estabelecida sem o adequado planejamento, colocando em risco a estabilidade dos ecossistemas afetados e provocando muitas vezes outros sérios danos ao ambiente.

Dados quantitativos sobre visitação em áreas de manguezal são raros na literatura. Dodemont (2006) realizou estudos sobre a visitação por escolas ao Parque Natural de Ilha Salamanca, localizado na costa caribenha da Colômbia. A autora aplicou questionários a professores e realizou entrevistas com funcionários do parque nacional e membros de ONGs, a fim de avaliar a percepção destes em relação ao ecossistema manguezal, e propor melhorias no enfoque pedagógico para a visitação nessa área natural. Segundo a autora, apesar dos manguezais fazerem parte da paisagem local, a relação dos entrevistados com esse ecossistema costeiro é limitada.

Segundo Cunha-Lignon (2007), o turismo em áreas de manguezal no Brasil, 
Caracterizando os Visitantes do Parque Estadual da llha do Cardoso (SP): subsídio para o planejamento de atividades turística-educacional em áreas de manguezal

deve ser valorizado e multiplicado, de modo que os futuros tomadores de decisão do país se conscientizem da riqueza e importância desse ecossistema. A autora destaca a necessidade do planejamento dessa atividade, a fim de se reduzir os impactos negativos, se aproveitar todo o potencial do ecossistema para conservação e para a prática da educação e do turismo ambiental. A visitação em áreas naturais deve procurar minimizar os impactos negativos da atividade e a maximizar a qualidade da experiência do visitante (BRASIL, 2003). Sendo necessária a adoção de mecanismos de monitoramento do impacto, assim como o estabelecimento de estratégias de manejo da visitação que busquem compatibilizar a conservação da natureza e a visitação em ambientes naturais.

Ainda não há qualquer referência a estudos sobre capacidade de carga ou de suporte em áreas de manguezal. O manguezal é um ecossistema complexo e altamente maleável. Ambientes com características distintas de granulometria do sedimento, temperatura, aporte de nutrientes dos rios, energia de rios e correntes de marés condicionam a zonação e o desenvolvimento estrutural da cobertura vegetal desse ecossistema (SCHAEFFER-NOVELLI et al., 1990). Apesar da alta resiliência das espécies típicas de mangue, responsável pela recuperação desses vegetais após sofrerem perturbações, essa característica nem sempre garante a recomposição total do ecossistema (CINTRÓN; SCHAEFFER-NOVELLI, 1992).

Os manguezais do Parque Estadual da Ilha do Cardoso recebeu visitas sistemáticas desde meados dos anos 90 . Os impactos da atividade turística nesse ecossistema foram monitorados, de 2001 a 2005. Ao longo do monitoramento, foram observadas as seguintes alterações nos bosques de mangue visitados: pisoteio de plântulas de espécies típicas de mangue, impacto na dinâmica de plântulas e propágulos, pisoteio de tocas de caranguejo, compactação do sedimento formando pequenos canais e alterando a circulação das marés, suspensão de sedimento fino e posterior deposição sobre raízes e troncos com sufocamento das estruturas respiratórias (lenticelas), quebras de raízes e troncos, entre outras (COELHO-JUNIOR, com. pess., 2007).

O estabelecimento da capacidade de carga, utilizando metodologias distintas, assim como o fechamento temporário de algumas trilhas foram citados como possíveis procedimentos de monitoramento dos impactos em parques estaduais do país (BRASIL, 2003). No mesmo diagnóstico, o estudo da capacidade de suporte e controle do tamanho dos grupos e número de visitantes foram citados como indicações para o estabelecimento de diretrizes para a visitação. Em relação à atividade de caminhada realizada em UCs, há a necessidade de análise criteriosa para o estabelecimento de trilhas em locais de ambientes sensíveis (BRASIL, 2006). Há necessidade de se elaborar projetos específicos para a construção ou recuperação das trilhas e estruturá-las de acordo com seus objetivos e considerando os seguintes aspectos: mínimo impacto sobre os recursos naturais, recursos disponíveis, necessidade dos usuários e critérios para a manutenção (BRASIL, 2006). Segundo Takahashi (1997 apud NIEFER, 2000), a capacidade de carga recreativa busca um número ideal de visitantes que uma área poderia tolerar em um dado período de tempo, sem causar danos excessivos. A autora destaca que não existe relação direta entre o número de visitantes e a quantidade de impactos negativos em uma área. Estes impactos estão mais ligados ao comportamento dos visitantes do que ao número de pessoas. Segundo Kataoka (2004), o entendimento das relações entre visitantes e as áreas naturais auxilia o manejo do uso público em UCs. 
Berchez et al. (2007), em sugestão de modelos de educação ambiental em UCs ligadas a ecossistemas marinhos, desenvolveram atividades em caiaques nos manguezais da Praia Dura (Ubatuba, litoral norte do Estado de São Paulo), denominada 'Trilha em Caiaque'. Segundo os autores, esse modelo teve pequeno número de visitantes em virtude de problemas logísticos, incluindo a dificuldade de acesso ao manguezal. Apesar disso, os autores afirmam que as atividades podem ser desenvolvidas em grupos fechados em outras UCs.

O principal público do Núcleo Perequê no PEIC era constituído por crianças do ensino fundamental. Atualmente, o pernoite de grupos não é mais realizado no PEIC. As visitas guiadas nos manguezais ainda são realizadas diretamente sobre o sedimento lodoso do ecossistema. Em 2010, construiu-se uma passarela de madeira para visitação do manguezal, mas a mesma encontra-se desativada. A falta de infraestrutura adequada para realização de tal atividade, as características intrínsecas ao manguezal e o comportamento dos visitantes ocasionaram inúmeros impactos negativos no ecossistema. Dessa forma, torna-se fundamental a definição de estratégias efetivas para reduzir os impactos sobre o ecossistema manguezal visitado nessa UC, de modo a se manter a visitação, sensibilizar os visitantes e promover conservação do ecossistema.

\section{Conclusões e Recomendações}

A grande maioria dos visitantes do Núcleo Perequê do Parque Estadual da llha do Cardoso (PEIC) participou de atividades educativas (estudo do meio ambiente), representados por grupos de escolas, que visitaram a UC com agências de turismo especializadas, durante o período do calendário escolar, permanecendo em torno de três dias.

Em média, 2.339 pessoas visitaram o PEIC, por ano. Considerando que apenas os grupos que pernoitaram no Núcleo Perequê do PEIC preencheram os questionários, a visitação efetiva nessa UC foi ainda maior, sendo realizada por grupos de excursionistas, que passaram somente o dia na UC e que também realizaram atividades nos ecossistemas.

Os dados quali-quantitativos da visitação no Núcleo Perequê do PEIC poderão dar subsídios ao planejamento das atividades turística-educacional, reduzindo os impactos negativos acarretados em áreas de manguezal, decorrentes da visitação.

A iniciativa do PEIC em aplicar questionários aos visitantes, que se hospedaram e pernoitaram na UC foi relevante. Seria de extrema importância que o mesmo fosse aplicado aos visitantes que não se hospedaram na UC, destacando-se os ecossistemas visitados por cada grupo, a fim de se obter dados mais fiéis sobre o número de pessoas que frequentaram os manguezais e os outros ecossistemas por unidade de tempo (mês, ano). A iniciativa poderia ser utilizada por outras UCs brasileiras, de modo a subsidiar medidas de gestão.

Por fim, sugere-se que a visitação nos manguezais do PEIC seja feita a partir de embarcações pequenas sem motor (canoas e caiaques) ou embarcações com motor, utilizando-se velocidade reduzida. Outras alternativas de infraestrutura, obedecendo as leis vigentes para o ecossistema manguezal em níveis nacional, estadual e municipal, também devem ser avaliadas, a fim de se atenuar os impactos negativos da visitação no ecossistema manguezal e se maximizar a qualidade da experiência do visitante. 
Caracterizando os Visitantes do Parque Estadual da llha do Cardoso (SP): subsídio para o planejamento de atividades turística-educacional em áreas de manguezal

\section{Referências bibliográficas}

AMOAMCA. Associação dos Monitores Ambientais de Cananéia. Disponível em http:// www.amoamca.com.br. Acesso em 12/08/2006, 2006.

AVAU, J., CUNHA-LIGNON, M.; DE MYTTENAERE, B.; GODART, M.F.; DAHDOUHGUEBAS, F. The commercial images promoting carribbean mangroves to tourists. Journal of Coastal Research, SI 64, v. II, pp.277-1281, 2011.

BERCHEZ, F.; GHILARDI, N.; ROBIM, M.J.; PEDRINI, A.G.; HADEL, V.F.; FLUCKIGER, G.; SIMÕES, M.; MAZZARO, R.; KLAUSENER, C.; SANCHES, C.; BESPALEC, P. Projeto trilha subaquática: sugestão de diretrizes para a criação de modelos de educação ambiental em Unidades de Conservação ligadas a ecossistemas marinhos. OLAM Ciência \& Tecnologia, Rio Claro / SP, Ano VII, Vol. 7, No. 3, Dezembro, pp.181-209, 2007.

BRASIL. Diagnóstico da visitação em parques nacionais e estaduais. Ministério do Meio Ambiente. Secretaria de Biodiversidade e Florestas. Diretoria de Áreas Protegidas. BrasíliaDF, 2003, 49p.

BRASIL. Diretrizes para Visitação em Unidades de Conservação. Ministério do Meio Ambiente. Secretaria de Biodiversidade e Florestas. Diretoria de Áreas Protegidas. Brasília-DF, 61p, 2006.

CANANET. Informaçoes sobre Cananéia desde 1999. Disponível em http:// www.cananet.com.br Acesso em 14/08/2006, 2006.

CINTRÓN, G. Caracterización y manejo de areas de manglar. Livro de Resumos do Simpósio sobre Ecossistemas da Costa Sul e Sudeste Brasileira, 1987.

CINTRÓN-MOLERO, G.; SCHAEFFER-NOVELLI, Y. Ecology and management of New World mangroves. In: SEELIGER, U. (ed.), Coastal Plant Communities of Latin America. 1992.

COSTA, C.M.N.; COSTA, V.C.; MELLO, F.A. Planejamento de trilhas no contexto do manejo e gestão do ecoturismo de unidades de conservação urbanas. OLAM Ciência e Tecnologia, Rio Claro - SP, Ano VII, Vol. 7, No 3, 115-136, 2007.

CUNHA-LIGNON, M. Le tourisme dans la mangrove au Brésil - un outil pour la conservation de la zone côtière. Panoramica Latinoamericana. Édition belge. $\mathrm{N}^{\circ} 39$, nov-déc, pp.9-10, 2007.

CUNHA-LIGNON, M.; ALMEIDA, R.; SCHAEFFER-NOVELLI, Y. Complexo Estuarino-Lagunar de Iguape-Cananéia: turismo $x$ conservação. Anais do $V$ Simpósio de Ecossistemas Brasileiros: conservação, Vol. I: 372-379, Vitória (ES), 2000.

DAVENPORT, J.; DAVENPORT, J.L. The impact of tourism and personal leisure transport on coastal environments: a review. Estuarine, Coastal and Shelf Science, 67: 280-292, 2006.

DIEGUES, A. C. Conservação e desenvolvimento sustentado dos ecossistemas litorâneos no Brasil. Anais do Simpósio sobre Ecossistemas da Costa Sul e Sudeste Brasileira, Vol. 3. São Paulo, 1987.

DODEMONT, S. Les enjeux du tourisme et de l'éducation à l'environnement dans les Parcs Nationaux. Etude du Parc National colombien de la Vía Parque Isla de Salamanca (VIPIS). Mémoire de Licence en Tourisme. Institut de Gestion de l'Environnement et d'Aménagement du Territoire, Université Libre de Bruxelles, 2006, 110p.

DUGAN, P.J. Conservación de Humedales: un análisis de temas de actualidad y acciones necesarias. IUCN, Gland, Suiza, 1992. 
GUAPYASSÚ, SMS. Análise da efetividade das ações de manejo e da proteção da biodiversidade em seis parques do Estado do Paraná. Dissertação de Mestrado, Universidade Federal do Paraná, , 2006, 232p.

HALL, C.M. Trends in ocean and coastal tourism: the end of the last frontier? Ocean \& Coastal Management. V.44, pp.601-618, 2001.

IBGE. Populaçao de Cananéia estimada em 01/07/2006. Site Cidades. Instituto Brasileiro de Geografia e Estatística. Disponível em http://www.ibge.gov.br/cidadesat/default.php. Acesso em 15 de junho de 2007, 2007.

KATAOKA, S.Y. Indicadores da qualidade da experiência do visitante no Parque Estadual da Ilha Anchieta. Dissertação de Mestrado, Universidade de São Paulo, Piracibaca, 200497p.

LUGO, A.E. Conserving Latin American and Caribbean mangroves: issues and challenges. Madera y Bosques. Número especial: pp.5-25, 2002.

MACIEL, N.C. Os manguezais e as unidades de preservação no Brasil. Anais do Simpósio sobre Ecossistemas da Costa Sul e Sudeste Brasileira: síntese dos conhecimentos, 1987.

NIEFER, I.A. Critérios para um ecoturismo, ambientalmente saudável. Dissertação de Mestrado em Engenharia Florestal - Universidade Federal do Paraná. Curitiba, 2000.

PEDRINI, A.G.; COSTA, C.; NEWTON, T.; MANESCHY, F.S.; SILVA, V.G.; BERCHEZ, F.; SPELTA, L.; GUILARDI, N.P.; ROBIM, M.J. Efeitos, ambientais da visitação turística em áreas protegidas marinhas: estudo de caso na piscina natural marinha, Parque Estadual da llha Anchieta, Ubatuba, São Paulo, Brasil. Revista OLAM, Ciência e Tecnologia, Rio Claro (SP), v. 8, n. 1, maio/junho, 22p, 2007.

RAMSAR. Ramsar Handbook for the wise use of wetlands. Handbook 5: Establishing and Strengthening local communities' and indigenous peoples's participation in the management of wetlands. San José, Costa Rica, 2000, 92p.

RAMSAR. Manuel Pour I'Utilisation Rationelle de Zones Humides. Manuel 5: Géstion

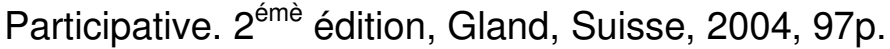

RODRIGUES, A.A.B. Turismo e Espaço: rumo a um conhecimento transdisciplinar. São Paulo, HUCITEC, 1997.

RUSCHMANN, D. Turismo e planejamento sustentavel: a proteção do meio ambiente. Campinas, Papirus Ed., $5^{a}$ ed., Coleção Turismo, 1999, 199p.

SÃO PAULO. Planos de manejo das unidades de conservação. Parque Estadual da do Cardoso. Fase 1-Plano de Gestão Ambiental. Secretaria de Meio Ambiente, São Paulo, 1998.

SÃO PAULO. Síntese do Projeto de Desenvolvimento do Ecoturismo na Região da Mata Atlântica, São Paulo. Secretaria de Meio Ambiente, GESP, Nov, São Paulo, 3p. http:// www.ambiente.sp.gov.br/EA/adm/admarqs/SergioSalvati.pdf. Acesso em 09/02/2008, 2005.

SATYANARAYANA, B.; BHANDERI, P.; DEBRY, M.; MANIATIS, D.; FORÉ, F.; BADGIE, D.; JAMMED, K.; VANWING, T.; FARCY, C.; KOEDAM, N.; DAHDOUH-GUEBAS, F. A SocioEcological Assessment Aiming at Improved Forest Resource Management and Sustainable Ecotourism Development in the Mangroves of Tanbi Wetland National Park, The Gambia, West Africa. AMBIO, pp.1-14, 2012.

SCHAEFFER-NOVELLI, Y.; CINTRÓN-MOLERO, G.; ADAIME, R.R.; CAMARGO, T.M. Variability of mangrove ecosystems along the Brazilan coast. Estuaries, v.13, n.2, pp.204-219, 1990. 
Caracterizando os Visitantes do Parque Estadual da Ilha do Cardoso (SP): subsídio para o planejamento de atividades turística-educacional em áreas de manguezal

SEABRA, L. Turismo Sustentável: planejamento e gestão. Cap. 5. In: CUNHA, S.B.; GUERRA, A.J.T. (orgs.), A questão ambiental: diferentes abordagens.. Rio de Janeiro, Bertrand Brasil, 2 ${ }^{\underline{a}}$ ed., 2005, pp. 153-189.

SILVA, J.F. Dados climatológicos de Cananéia e Ubatuba (Estado de São Paulo). Bolm. climatol. Inst. oceanogr, São Paulo, 1989.

SNUC. Sistema Nacional de Unidades de Conservação, Lei $N^{\circ} 9.985$, de 18 de julho de 2000, 2000.

\section{Agradecimentos}

As autoras agradecem Marcos Campolim, Diretor do Parque Estadual da Ilha do Cardoso (PEIC) entre 2004 a 2009, pela cessão dos questionários utilizados no presente trabalho. Aos funcionários do PEIC e monitores ambientais, da Associação de Monitores Ambientais de Cananéia (AMOAMCA), pelas importantes informações sobre as atividades realizadas nessa unidade de conservação. Ao Dr. Clemente Coelho Junior, presidente do Instituto Biomabrasil, pelas informações a respeito dos impactos e do monitoramento dos manguezais do PEIC.

Hélita Maria Teixeira Moaes: Prefeitura Municipal de Praia Grande, Praia Grande, SP, Brasil

Email: hetinha21@hotmail.com

Link para o currículo Lattes: http://lattes.cnpq.br/9270546772912832

Marília Cunha Lignon: Université Libre de Bruxelles (ULB), Bélgica, e Universidade Federal de São Paulo, São Paulo, SP, Brasil.

Email: cunha.lignon@gmail.com

Link para o currículo Lattes: http://lattes.cnpq.br/6396735236608800

Data de submissão: 05 de junho de 2012

Data de recebimento de correções: 26 de julho de 2012

Data do aceite: 26 de julho de 2012

Avaliado anonimamente 